\title{
Formation of Microphase-Separated Structure in a Triblock Copolypeptide LB Film
}

\author{
Toshihiko Niwa, Akiyoshi Kato, Masayoshi Tanaka, and Takatoshi Kinoshita
}

\author{
Graduate School of Engineering, Nagoya Institute of Technology, Gokiso-cho, Showa-ku, \\ Nagoya 466-8555, Japan
}

\begin{abstract}
In order to construct an intelligent functional nano-interface, the self-organized structure of LangmuirBlodgett (LB) films was studied using a well-defined triblock copolypeptide amphiphile as a film component. A surface structure of the LB film expressed a stripe nano-pattern unit assembly based on a phase separation. This note describes the effect of surface pressure and $\mathrm{pH}$ of the subphase water on the monolayer formation of the copolypeptide at the airwater interface.
\end{abstract}

(Received 15 May, 2006 ; Accepted 4 October, 2006)

\section{Introduction}

Polypeptides include well-defined structures and site-specific functions. The character of the constitutive amino acids and the sequence promote to form favorable secondary structures, and these structural units selfassemble into a specific higher-ordered nano-organization. Actually, versatile supramolecular architectures selfassembled with designed peptides were reported as to nanofibers [1], nanotubes $[2,3]$, nanoribbons $[4]$ and vesicles [5] etc. Moreover, peptide structures are known to vary with the ambient conditions such as $\mathrm{pH}$, solvent, temperature, external forces, etc., which has attracted much attention in the field of biomimetic chemistry.

In recent years, many researchers have tried to create functional nano-devices in which molecular elements are orderly located on a solid plate [6]. For material application, it is important to construct well-defined twodimensional nanometer scale patterning. We have investigated, utilizing the air-water interface, possibilities of a precise control of ordered arrangement in $\alpha$-helical polypeptide assembles [7]. An $\alpha$-helical peptide offers the well-defined and rigid rod-like structure with the controlled molecular length and side chain placement. Our previous study $[8,9]$ with respect to the LangmuirBlodgett (LB) film of di- and triblock $\alpha$-helical copolypeptides showed that a two-dimensional stripe pattern based on a phase-separated structure, suggesting the effect of molecular conformation on the monolayer structure formed.

In this study, we prepared a triblock copolypeptide amphiphile as a rod-like building block, and investigated monolayer characteristics of the copolypeptide at an airwater interface. The triblock copolypeptide was prepared to comprise a terminal, hydrophobic poly $(\gamma$-benzyl Lglutamate) blocks flanking a central, hydrophilic poly(L- lysine), as shown in Fig. 1. Two-dimensionally organized monolayer built from this triblock copolypeptide produced alternate thick/thin lane-like domains, a stripe pattern on nanometer scale, which is widely developed in micrometer scale. In addition, $\mathrm{pH}$ response of the ordered surface structure in the copolypeptide LB films is also described here.
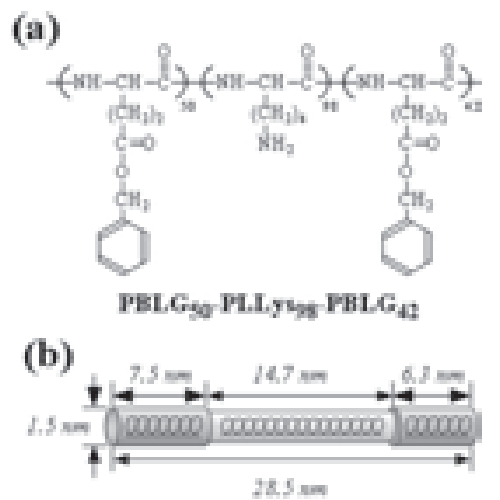

Fig. 1 Chemical structure (a) and schematic illustration (b) of $\mathrm{PBLG}_{50}-\mathrm{PLLyS}_{98}-\mathrm{PBLG}_{42}$.

\section{Experimental}

\subsection{Material preparation}

The triblock copolypeptide amphiphile used in this study (Fig. 1), poly( $\gamma$-benzyl L-glutamate)-block-poly(Llysine)-block-poly( $\gamma$-benzyl L-glutamate) (PBLG-PLLysPBLG), was synthesized by transition metal-mediated Ncarboxy anhydride (NCA) polymerization, which allows control over polypeptide chain length and composition [10]. The molecular length and the rod diameter of each $\alpha$-helical block were determined from a helical pitch of $0.15 \mathrm{~nm}$ per an amino acid residue and previously described papers $[11,12]$. ${ }^{1} \mathrm{H}-\mathrm{NMR}$ measurement was 
carried out for the polypeptides of PBLG $\mathrm{G}_{\mathrm{l}}, \mathrm{PBLG}_{\mathrm{l}}-\mathrm{PLLys}_{\mathrm{m}}$ and $\mathrm{PBLG}_{\mathrm{l}}-\mathrm{PLLys}_{\mathrm{m}}-\mathrm{PBLG}_{\mathrm{n}}$ obtained after the block polymerizations, and the average polymerization numbers were determined as PBLG $_{1}-$ PLLys $_{\mathrm{m}}-\mathrm{PBLG}_{\mathrm{n}}(\mathrm{l}=50, \mathrm{~m}=98$ and $n=42$ ). Circular dichroism spectroscopy measurement confirmed that the copolypeptide form an $\alpha$-helical conformation as illustrated in Fig. 1(b).

\subsection{Surface pressure-area isotherm measure- ment and Langmuir-Blodgett film}

The surface pressure-area isotherms were obtained by the Wilhelmy method using a microprocessorcontrolled Langmuir-Blodgett film balance, NLE-BIO40MWCT (Nippon Laser Electronics Lab., Japan) at $25^{\circ} \mathrm{C}$. The surface pressure was determined with a precision of $1.0 \times 10^{-4} \mathrm{~N} / \mathrm{m}$. The Teflon trough was filled using the Milli-Q water purified $(\rho>18 \mathrm{M} \Omega \mathrm{cm})$ with the Milli-Q system (Millipore Ltd.). The subphase $\mathrm{pH}$ was kept at $\mathrm{pH}$ 10 , which was adjusted with $10 \mathrm{~N} \mathrm{NaOH}$. A chloroform/ DMF (1/1) solution of the copolypeptide $\left(1.2 \times 10^{-5} \mathrm{M}\right)$ was spread onto the water of $\mathrm{pH} 10$, and then after evaporation time of the solvent (more than 10 minutes), the monolayer on the water was compressed continuously with the rate of $2.25 \mathrm{~mm}^{2} \mathrm{~s}^{-1}$. The isotherm confirmed steep increase in the surface pressure when the copolypeptide layer was compressed by a barrier, suggesting that the copolypeptide performs stable membrane formation.

After relaxation time of about 30 minutes at the surface pressure $0,0.5,4,8$ and $12 \mathrm{mN} / \mathrm{m}$, respectively, the monolayer was transferred onto a freshly cleaved mica substrate by the vertical dipping method (transfer rate of $5 \mathrm{~mm} / \mathrm{min}$ at up-stroke motion).

Two kinds of the LB films at the air-water interface were prepared as follows. After the monolayer was stabilized at the surface pressure of $4 \mathrm{mN} / \mathrm{m}$ for 10 minutes, the $\mathrm{pH}$ of the subphase was changed from 10 to 4 by addition of $6 \mathrm{~N} \mathrm{HCl}$ using a microsyringe. And then, the monolayer was transferred onto a mica substrate. A LB film with changes in the $\mathrm{pH}$ from 10,4 to 10 was also prepared. And then, the monolayer was transferred onto a mica substrate.

\subsection{Atomic force microscopy (AFM) observation}

Atomic force microscopy (AFM) observation was carried out using a NanoScope IV (Digital Instruments) AFM using a silicon cantilever with a spring constant of $32 \mathrm{~N} / \mathrm{m}$ (NCH-10V, Veeco Instruments) operated in tapping mode. All the images were recorded in air at room temperature. A $10 \mu \mathrm{m} \times 10 \mu \mathrm{m}$ scanner was used for imaging. The scanning speed was at a line frequency of $1 \mathrm{~Hz}$, and the original images were sampled at a resolution of $512 \times 512$ points.

\section{Results and discussion}

Surface pressure-area isotherm measurement for the triblock copolypeptide on the water of $\mathrm{pH} 10$ showed steep increase in the surface pressure when the copolypeptide layer was compressed by a barrier, suggesting that the copolypeptide performs stable membrane formation.

To elucidate monolayer formation process on the water, we investigated surface morphology of the LB films transferred at 0 and $8 \mathrm{mN} / \mathrm{m}$ of surface pressure, respectively, using AFM. The AFM image of the LB film transferred at the surface pressure of $0 \mathrm{mN} / \mathrm{m}$ showed a branch-like extended molecular layer (Fig. 2(a)). A nanometer-scaled AFM image was obtained by magnification of the square-marked region in Fig. 2(a). This revealed a two-dimensional phase-separated structure composed of alternate thick/thin lane-like domains, like a stripe pattern, in the membrane obtained at the surface pressure of $0 \mathrm{mN} / \mathrm{m}$. The interval of nanostripe unit was estimated to be $\sim 28 \mathrm{~nm}$, and was consistent with the calculated molecular length in Fig. 1 (b). The AFM image of the LB film transferred at the surface pressure of $8 \mathrm{mN} / \mathrm{m}$ in Fig. 2(b) showed a uniform, randomly-oriented phase-separated structure with a nano-stripe unit as well as the above-discussed surface structure in Fig. 2(a). The film thickness was estimated to be ca. $1.61 \mathrm{~nm}$ from the depth of the cavity that was made by scratching with a cantilever. This value is almost consistent with the diameter of the $\alpha$-helix, which indicates that the $\alpha$-helix rods lie down on the mica surface. These AFM results suggest that the triblock copolypeptide amphiphiles firstly self-organized into the two-dimensional stripe nano-patterned unit based on the

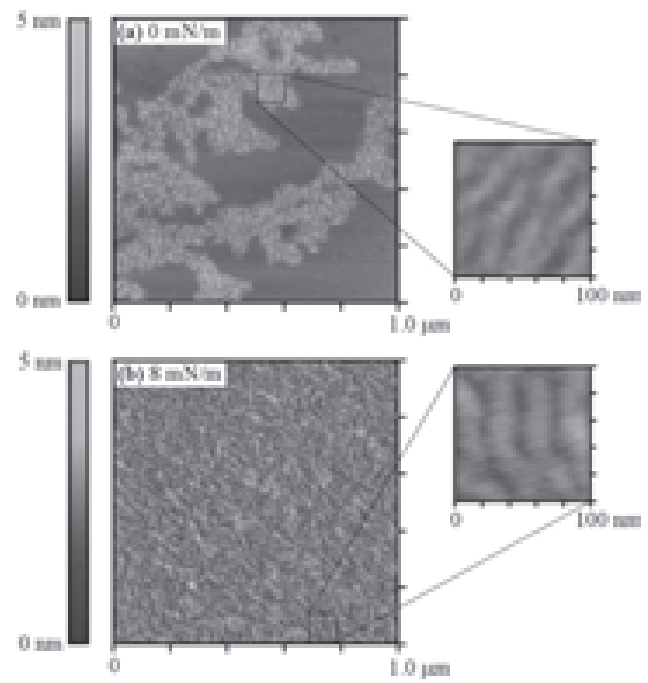

Fig. 2 AFM images of the triblock copolypeptide LB films of each deposition pressure; (a) $0 \mathrm{mN} / \mathrm{m}$ and (b) $8 \mathrm{mN} / \mathrm{m}$. 
phase-separated structure when stabilized on the water, which is composed of the thick hydrophobic lane of PBLG and thin hydrophilic lane of PLLys, followed by several micrometer-scaled lane-like domains with a random orientation developed with compression of the units. Slightly bent stripes in the nano-pattern, as shown in the magnified AFM images of $100 \mathrm{~nm}^{2}$, may be due to the asymmetry of the triblock copolypeptide (difference in the length of the hydrophobic $\alpha$-helix blocks). AFM observation for the surface structure of several LB films (surface pressure : $0.5,4$ and $12 \mathrm{mN} / \mathrm{m}$ ) also showed, in the above-mentioned manner, a closely-packed state in proportion to the surface pressure of the monolayers, and supported this conjecture (the data are not shown).

Poly(lysine) is known to have a hydrophilic amino acid residue that can be cationic-charged, and then form an $\alpha$-helix conformation in higher $\mathrm{pH}$ aqueous media and, on the other hand, form a random coil in lower $\mathrm{pH}$ owing to ionic repulsion. With consideration for this property, we observed here the surface structure of the solid-state LB films after the subphase $\mathrm{pH}$ changes from $\mathrm{pH} 10$ to pH 4 in Fig. 3(a) and from pH 10, pH 4 to pH 10 in Fig. 3 (b) under constant surface pressure $(8 \mathrm{mN} / \mathrm{m})$. The surface structure showed the well-defined nano-stripe pattern in Fig. 3(b), however no clear pattern was observed in Fig. 3(a). The film thickness was also confirmed to recover the original one, i.e., that of the monolayer of $\mathrm{pH} 4$, estimated to be $2.1 \mathrm{~nm}$ (Fig. 3(a)), was decreased to $1.6 \mathrm{~nm}$ at pH 10 (Fig. 3(b)). This is due to the structural transition between the bulky random coil and $\alpha$-helix of the PLLys block in the copolypeptide.

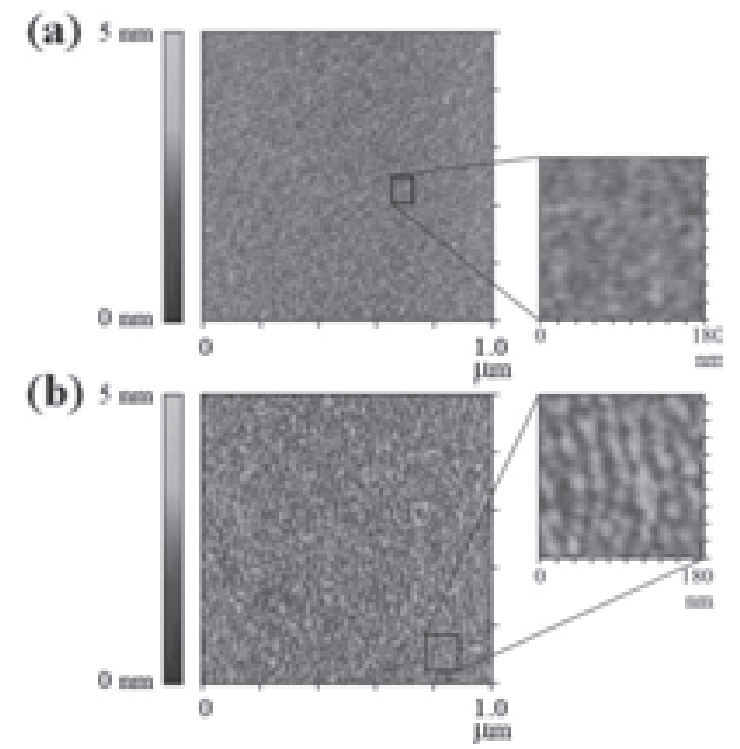

Fig. 3 AFM images of the triblock copolypeptide LB film when the subphase $\mathrm{pH}$ changes ; (a) from $\mathrm{pH}$ 10 to $\mathrm{pH} 4$ and (b) from $\mathrm{pH}$ 10, $\mathrm{pH} 4$ to $\mathrm{pH} 10$.

\section{Conclusion}

We proposed here establishment of molecular membrane system to control two-dimensional nanopattern structure based on the phase separation and subphase $\mathrm{pH}$. Inherent intermolecular interactions of a peptide, e.g. hydrophobic and ionic interactions here, were effectively used to achieve the above system. Ordered stripe interval may be controllable with molecular weight (length) of a building block. In addition, peptide design may cause several molecular conformations (shapes) and the resultant various patterns according to the external conditions. Current study in our laboratory is underway to make clear the kinetic selfassembling behaviors using designed block copolypeptides with controlled amino acid sequence.

\section{Acknowledgment}

This research was supported in part by a grant from the NITECH 21st Century COE Program, "World Ceramics Center for Environmental Harmony".

\section{References}

1. J. D. Hartgering, E. Beniash, and S. I. Stupp, Proc. Natl. Acad. Sci. USA, 99, 5133-5138 (2002).

2. R. Djalali, Y. Chen, and H. Matsui, J. Am. Chem. Soc., 125, 5873-5879 (2003).

3. M. Raches and E. Gazit, Science, 300, 625-627 (2003).

4. C. W. G. Fishwick, A. J. Beevers, L. M. Carrick, C. D. Whitehouse, A. Aggeli, and N. Boden, Nano Lett., 3, 1475-1479 (2003).

5. S. Vauthey, S. Santoso, H. Gong, N. Watson, and S. Zhang, Proc. Natl. Acad. Sci. USA, 99, 5355-5360 (2002).

6. E. T. Powers, S. I. Yang, C. M. Lieber, and J. W. Kelly, Angew. Chem. Int. Ed., 41, 127-130 (2002).

7. H. Yokoi, S. Hayashi, and T. Kinoshita, Prog. Polym. Sci., 28, 341-357 (2003).

8. H. Yokoi, T. Kinoshita, Y. Tsujita, and H. Yoshimizu, Chem. Lett., 10, 1210-1211 (2000).

9. H. Yokoi, S. Mizutani, and T. Kinoshita, Trans. MRS-J., 27, 551-554 (2002).

10. T. J. Deming, Nature, 390, 386-390 (1997).

11. H. L. Yakel Jr., Acta Cryst., 6, 724-727 (1953).

12. R. L. Shuler and W. A. Zisman, Macromolecules, 5, 487-492 (1972). 